\title{
Building a Geometallurgical Model for Orapa Diamond Mine, Botswana
}

\author{
Matthew Field $^{1}$, Oupa Gilika ${ }^{2}$ Kganetso Maphane ${ }^{2}$, Rebaone Letchuti-Tlawera ${ }^{3}$ and \\ ${ }^{1}$ Amec Foster Wheeler, matthew.field@amecfw.com \\ ${ }^{2}$ Debswana, Orapa Mine, ogilika@debswana.bw \\ ${ }^{2}$ Debswana, Orapa Mine, kmaphane2@debswana.bw \\ ${ }^{3}$ Debswana Corporate Centre, RLechuti-Tlhalerwa@debswana.bw \\ ${ }^{4}$ Anglo American plc, martin.roberts@angloamerican.com
}

\section{Introduction}

Geometallurgical models have become a major component of the management of ore reserves in many metalliferous mining operations. These models have at their core the mineralogy and other rock characteristics that affect the efficient liberation of the desired metals. For kimberlite ore bodies, the requirements are somewhat different because the optimal extraction of diamonds require a somewhat different approach that focusses on different parts of a typical diamond recovery process plant flow sheet, namely comminution, the removal of fine-grained materials below the economic bottom cut-off size of diamonds (so-called slurry and slimes), dense-media separation (DMS) concentration processes and the final recovery of diamonds from the concentrate. The challenge for building a geometallurgical model for a diamond mine is to identify, quantify and model suitable characteristics in the in-situ ore. This model can then be used to estimate the efficiency of these four main areas of the production plant during ore processing.

At Orapa a great wealth of data has been collected during the most recently completed resource extension project (OREP), but this data was not collected with a geometallurgical fore-thought as an end product. These data include standard geological and geotechnical logging procedures, wet- and dry- bulk density measurements, internal dilution measurements, geotechnical rock hardness measurements, drop-weight testing for comminution parameters, slurry and slimes fraction mineralogy determination by XRD and geochemical analysis of made-up slurry mixtures.

In addition monthly production records from the ore processing plant for the last decade were made available together with the monthly mining blends of ore sourced from different positions in the open pit and from a variety of lithologically controlled stockpiles. These data were used to assess the lithological effects of variable ore on the performance of the process plant over the last decade, and provide confirmation of how the varying characteristics impact plant performance.

\section{Geoscientific Data Acquisition}

The following data were selected for modelling for each of the processing areas:

Rock hardness: Rock quality designation (RQD), uniaxial compressive strength (UCS), Brazilain tensile strength, the $t_{10}$ and $t_{a}$ parameters from drop-weight tests.

DMS Yield: DMS yield percentages obtained by processing large-daimeter (24-inch) drill (LDD) product through a DMS bulk sample plant, but adjusting the yields back to insitu mass per sample.

Slurry/Slimes: Mineralogy determined by X-ray diffraction analysis of two size fractions, $-300 \mu \mathrm{m}$ and $-5 \mu \mathrm{m}$. The latter being performed using the glycolation process to ensure accurate identification of clay-mineral species. Also geochemical analyses conducted on slurries made from mixing clayfraction sample rock powders with samples of Orapa process water. These analyses provided exchange cation concentrations $\left(\mathrm{Na}^{+}, \mathrm{K}^{+}, \mathrm{Ca}^{+}\right.$and $\left.\mathrm{Mg}^{2+}\right)$ that are used to calculate the sodium- 
exchane capacity (ESP) of the slurry, which affects whether clay minerals settle or are dispersed in the slurry.

Final recovery: Specific tests were conducted to determine the percentage of $\mathrm{x}$-ray luminescent gangue minerals in the DMS concentrates of the LDD samples.

\section{Modellling Procedures}

After standard exploratory data analysis was completed, each of the datasets were examined to remove extreme outliers where appropriate, and this data was captured in Datamine Studio 3 software where geostatistical analysis was undertaken.

The different variables require different approaches to modelling, since some are considered linear and additive e..g DMS Yield and mineralogy percentages, whilst others are non-additive, e.g the various rock hardness variables. For the former, ordinary kriging can be used for estimation purposes, whilst for the latter multiple indicator kriging was employed, where various threshold values were used and probabilities estimated for each block exceeding those thresholds.

The most recent update of the geological model for Orapa A/K1 (see Maphane et al., this volume) was used for domain control of the estimation process.

Validation of the estimates was conducted using multiple estimation techniques such as nearest neighbour, local average, inverse distance squared and kriging (ordinary or multiple indicator where approriate). The estimates were compared against each other and against original sample data. In all cases the kriged estimates produced the most satisfactory results that best represent the sample data.

\section{Results}

Examples of the outcomes for DMS Yield (an example of a simple additive variable) and unixial compressive strength (or UCS - a non-additive variable) are shown in Figure 1 and Figure 2 respectively.

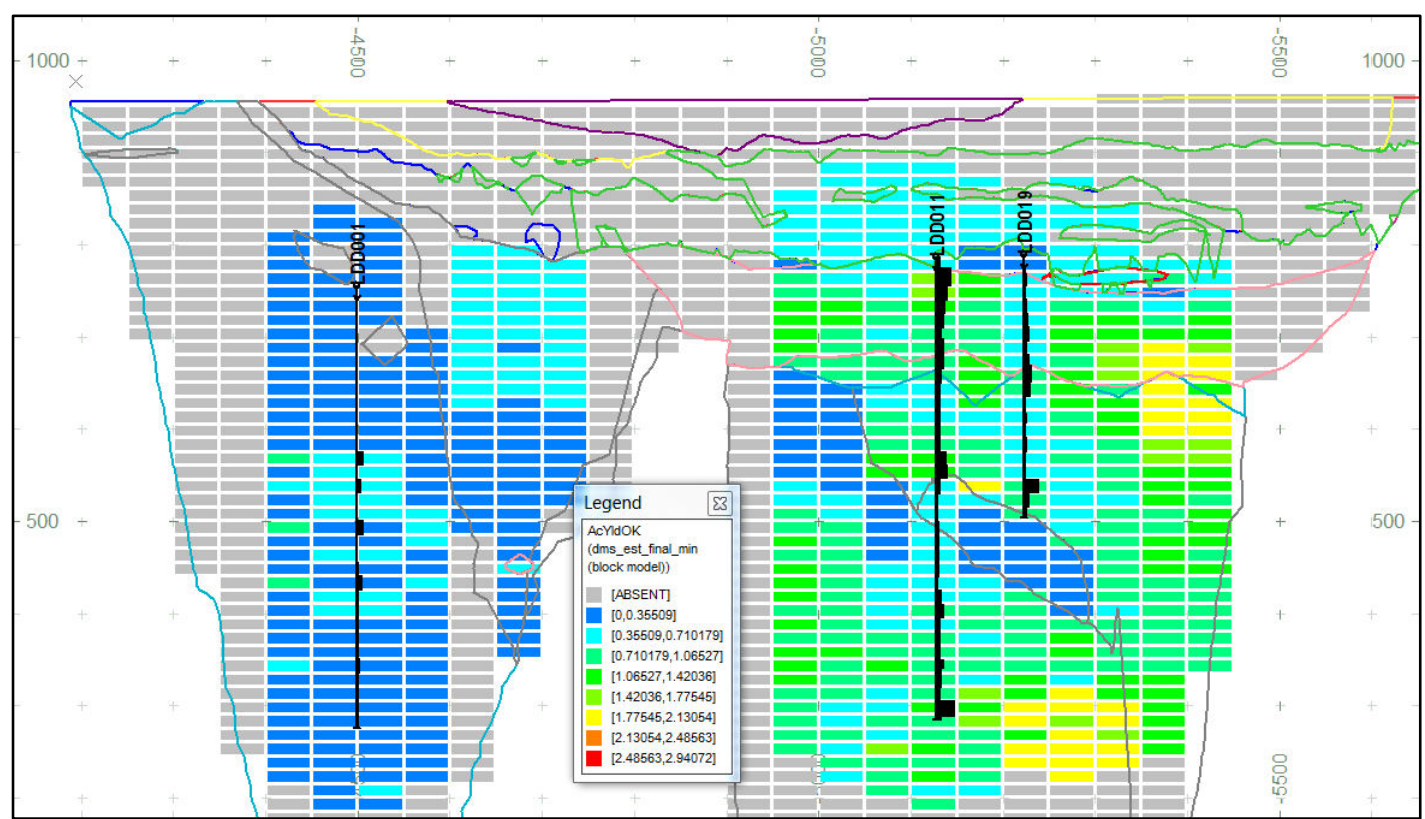

Figure 1: North-south vertical section through Orapa A/K1 with estimated DMS Yield values per block. LDD holes on the section are shown in black. Grid nodes are $100 \mathrm{~m}$ x $100 \mathrm{~m}$, 


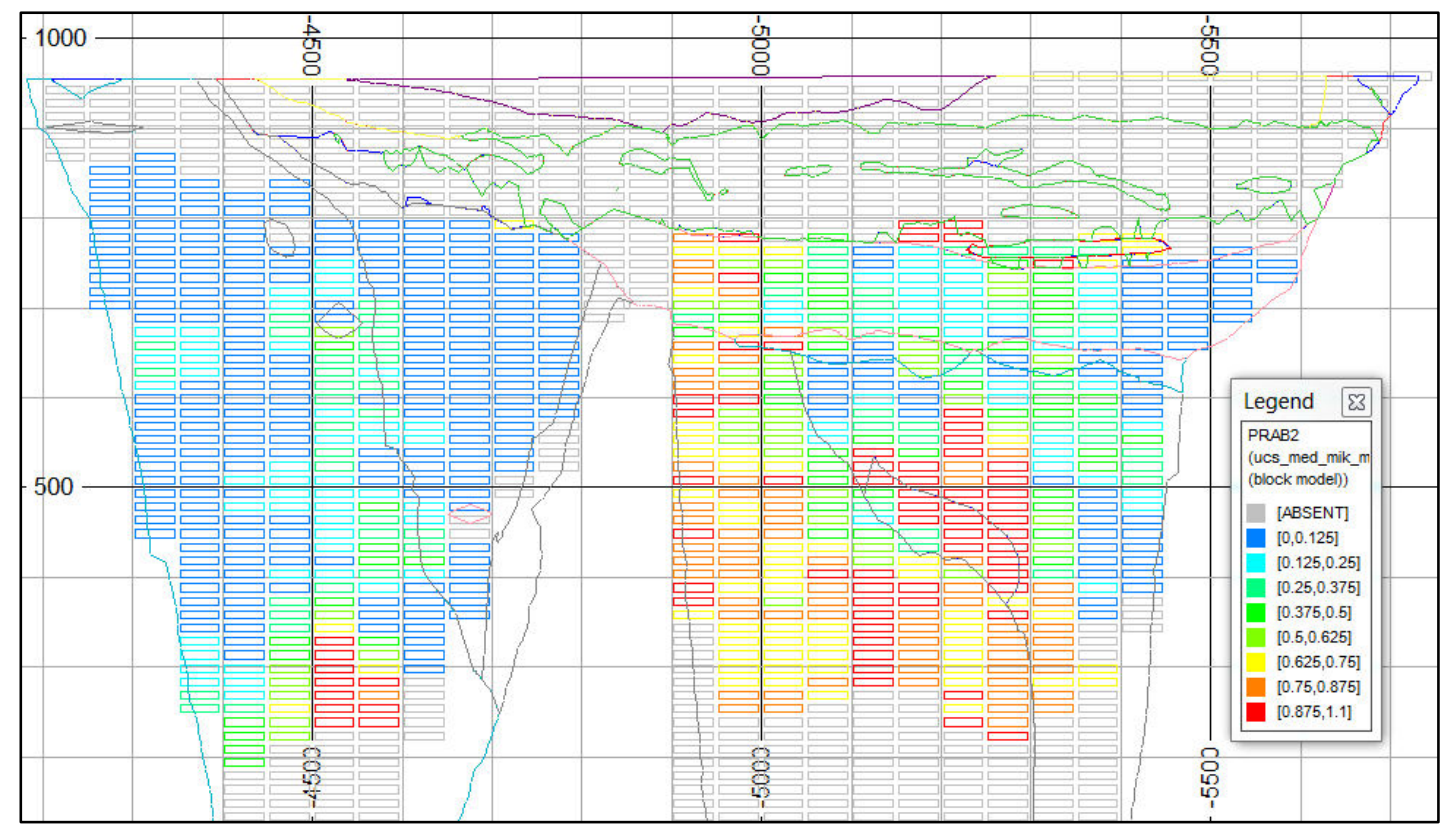

Figure 2: North-south section of Orapa A/K1 with estimated block values of rock hardness here expressed as the probabiltiy of UCS exceeding $40 \mathrm{MPa}$ in each block. Grid is $100 \mathrm{~m}$ x $100 \mathrm{~m}$.

\section{Production Data Analysis}

Production at Orapa is from many different discrete sources (up to 17 in any one month) that include the different lithological domains, but also a variety of stockpiles most of which have a specific lithological source.

The complex relationship between the variety of sources and aggregated monthly measurements taken in the plant, requires specialised statistical analysis. Here cumulative sum and recursive partitioning methods have been applied, and these provide quantitative evidence of the influence of various rock parameters on plant performance. A good example is that the percentage of basalt breccias influences power consumption, but also the quantity of material that does not crush below $25 \mathrm{~mm}$ during primary crushing.

All of the parameters measured point to a major change in plant operating conditions when mining transition from $t$ the SVK_U and through to the SVK_M geological domain.

\section{Conclusion}

All of the data gathered and modelled have been successfully intergrated into a geometallurgical model, that not only validates the geological model, but also provides Orapa mine planners with a tool to evaluate future production scenario regarding plant throughput efficiencies. This has been achieved through using standard geological and geotechnical measurements on drill cores obtained during the resource extension project, supplemented with specific metallurgical sampling campaigns on core that remained once all other sampling had been completed.

\section{References}

Maphane, K, 2017, Evolution of the Orapa A/K1 Geology Model - Insights from Analysis of MultiDisciplinary Datasets 